\title{
Laboratory investigation of interface shearing in chalk
}

\author{
Derek L.H. Chan ${ }^{1, *}$, Róisín M. Buckley ${ }^{2}$, Tingfa Liu $^{3}$, and Richard J. Jardine ${ }^{3}$ \\ ${ }^{1}$ Tony Gee \& Partners, London, UK \\ ${ }^{2}$ Oxford University, UK \\ ${ }^{3}$ Imperial College London, London, UK
}

\begin{abstract}
Chalk, a soft fine-grained Cretaceous limestone, is encountered across northern Europe where recent offshore windfarm, oil, gas and onshore developments have called for better foundation design methods, particularly for driven piles whose shaft capacities are controlled by an effective stress Coulomb interface failure criterion. Interface type and roughness is known to affect both interface friction angles, $\delta^{\prime}$ and the magnitude of dilation required for shaft failure to develop. Site-specific interface ring-shear tests are recommended for offshore pile design in sands and clays to account for driven pile shaft materials, roughnesses and shear displacements. However, few such tests have been reported for chalks and it is also unclear whether $\delta^{\prime}$ angle changes contribute to the striking axial capacity increases, or set-up, noted over time with piles driven in chalk. This paper describes an interface shear study on low-to-medium density chalk from the St. Nicholas-at-Wade research test site in Kent, UK, where extensive field driven pile studies have been conducted $[1,2]$. Direct shear and Bishop ring shear apparatus were employed to investigate the influences of interface material and surface roughness, as well as ageing under constant normal effective stresses $\left(\sigma_{n}{ }^{\prime}\right)$. It is shown that the high relative roughness of the interface compared to the chalk grain size results in the ultimate interface shearing angles falling close to the chalk-chalk shearing resistance angles. The $\delta^{\prime}$ angles also increased by up to $5^{\circ}$ over 38 days of ageing.
\end{abstract}

\section{Introduction}

Chalk is a weak rock, with Unconfined Compressive Strengths (UCS) ranging from $<1.25 \mathrm{MPa}$ to more than $12.5 \mathrm{MPa}$ [3], in which pile driving and load testing can be problematic and uncertain; [see 1,4].

Recent research, motivated by major offshore windfarm and onshore infrastructure developments, has led to increased understanding of chalk behaviour. New preliminary design rules have been proposed for piles in low-medium density chalk, which tend to mobilise very low shaft resistances during driving that subsequently increase significantly over time $[1,5]$. Dynamic compaction can easily de-structure chalk and pile driving creates a zone of very soft puttified material around pile shafts that consolidates to form an annular region of permanently lower water content $[1,6,7]$. The peak shearing resistances of remoulded chalk, as developed in triaxial tests, generally fall in the $29<\varphi_{\text {peak }}{ }^{\prime}<34^{\circ}$ range with low cohesion values $\mathrm{c}^{\prime}$ of $0-10 \mathrm{kPa}$ [8-12]. Triaxial tests that have attempted to replicate the effects of ageing observed in the field have shown little change in peak or critical state effective stress shear strength parameters over time, but have indicated significant increases in yield stresses and small-strain stiffness $[6$, $10,13]$.

The shaft capacities of piles driven in sands and clays are controlled by an effective stress Coulomb interface failure criterion. The operational associated angles of interface friction, $\delta^{\prime}$ between the soil and the pile construction material, can be no greater than the soil-soil shear strengths $\varphi^{\prime}$ and generally reduces with interface roughness; [14]. Empirical relationships between $\delta^{\prime}$ and $\varphi^{\prime}$ have been proposed [e.g. 15] but are insufficiently reliable for pile design. Site-specific testing employing representative interfaces, roughnesses and shearing histories is recommended for offshore pile design [16].

[2] demonstrated that, as with sands and clays, pile shaft failure in chalk is controlled by the Coulomb failure criterion. The preliminary design rules for piles driven in chalk outlined by [17] call for representative $\delta^{\prime}$ measurements. The limited sets published data for interface shear tests on chalk indicate ultimate $\delta^{\prime}$ values of $\approx 30.5^{\circ}$ falling below the chalks' typical $\varphi^{\prime}$ values and possibly being affected by the shear displacements and normal stress levels imposed during testing [18, 19]. There are no reports of shear tests on "aged" chalk samples and interface of which the Authors are aware.

This paper describes a series of interface shear tests on samples of low-medium density chalk from the Imperial College (IC) chalk test site at St Nicholas-atWade in Kent, UK. The tests, carried out in the direct shear apparatus and the [20] ring shear apparatus at IC, investigated: (i) the residual interface shear strength of remoulded chalk; (ii) the effects of interface roughness and material (mild steel or stainless steel) on the interface shear strength; and (iii) the effects of ageing under constant normal effective stress. 


\section{Description of the sampling site}

The study employed samples from the Imperial College (former chalk quarry) test site. The site, which was described by [1], is currently the focus of ongoing experimental investigation by Imperial College (IC) and Oxford University [21] under the ALPACA Joint Industry Project. The sampled chalk belongs to the Margate White chalk subgroup, which consists of $98.6 \%$ of calcium carbonate [22], is of low-to- medium density and classifies as structured CIRIA grade B2/B3 [3]. Laboratory hydrometer tests suggested predominantly silt-sized particles (Fig. 1), which is consistent with previously reported analyses of chalk [13, 23].

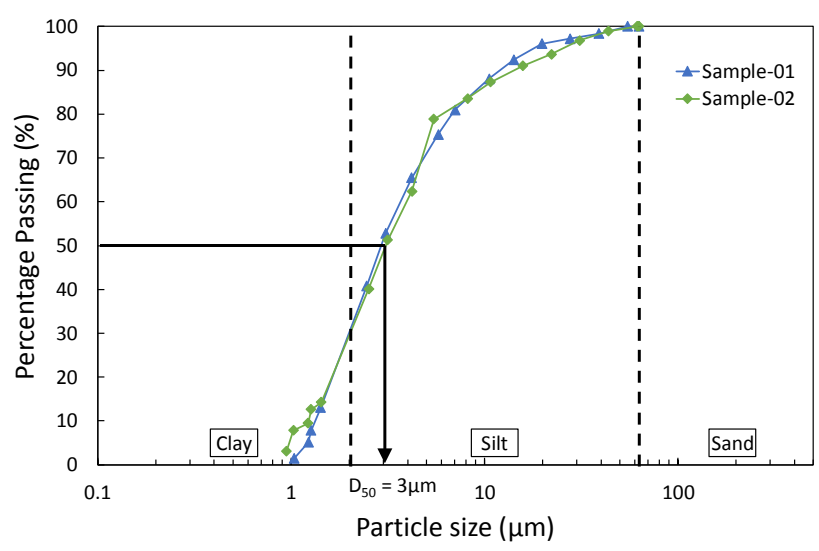

Fig. 1 Particle size distribution of crushed chalk from St Nicholas-at-Wade

\section{Experimental procedures}

\subsection{Sample and interface preparation}

Two types of interfaces were employed. Stainless (SS) and Mild (MS) Steel interfaces which were prepared by air abrasion to achieve relatively smooth (SMT) $\left(\mathrm{R}_{\mathrm{a}}<2\right.$ $\mu \mathrm{m})$, standard (STD) $\left(2<\mathrm{R}_{\mathrm{a}}<10 \mu \mathrm{m}\right)$ and rough $(\mathrm{RGH})$ $\left(\mathrm{R}_{\mathrm{a}}>10 \mu \mathrm{m}\right)$ surfaces. Their average centre line roughnesses $R_{a}$ were measured before and after testing by a Taylor Hobson "Talysurf" profiling machine in the Imperial College tribology laboratories.

The tested material was prepared by placing initially dry chalk blocks into a grinder with the addition of small amount of deionised water, which rapidly produced a uniform putty with $\mathrm{D}_{50} \approx 3 \mu \mathrm{m}$ as shown in Fig. 1. Similar work by [13] on samples from the same site indicated a value closer to $6 \mu \mathrm{m}$. The grading depends on the preparation method and $\mathrm{D}_{50}$ values as low as $1 \mu \mathrm{m}$ are possible [12]. The initial water content of the prepared putty fell in the range of $23-26 \%$.

[24] described details of the testing methodology and programme for the direct shear and ring shear experiments reported herein.

\subsection{Direct shear tests}

The tested specimens were formed by placing the prepared chalk putty in direct shear and ring shear moulds in two to three layers. Six interface tests were executed in direct shear boxes under a normal effective stress of $200 \mathrm{kPa}$, which was applied with a few load steps with short intervals. The loading stages showed that the primary consolidation of the specimens completed almost instantaneously, reflecting the high permeability of the chalk putty material.

Table 1 summarises the testing programme on remoulded chalk, which involved transverse shear rates of $0.048-0.4 \mathrm{~mm} / \mathrm{min}$. Both SS and MS interfaces with SMT and RGH roughnesses were used. One direct shear test involving an MS interface was "aged" for 38 days in the apparatus under $200 \mathrm{kPa}$ while submerged in deionised water prior to shearing. The shear box tests' shearing stages continued until $10 \mathrm{~mm}$ of displacement had been achieved.

Table 1 Direct shear testing programme

\begin{tabular}{cccc}
\hline Test Code & $\begin{array}{c}\text { Initial } \\
\mathbf{R}_{\mathbf{a}} \\
(\boldsymbol{\mu \mathbf { m } )}\end{array}$ & $\begin{array}{c}\text { Post- } \\
\text { test } \mathbf{R}_{\mathbf{a}} \\
(\boldsymbol{\mu} \mathbf{m})\end{array}$ & $\begin{array}{c}\text { Shearing } \\
\text { rate } \\
(\mathbf{m m} / \mathbf{m i n})\end{array}$ \\
\hline MS-RGH-064 & 14.33 & - & 0.064 \\
MS-SMT-064 & 5.58 & 3.63 & 0.064 \\
SS-RGH-064 & 13.02 & 11.21 & 0.064 \\
SS-SMT-064 & 1.22 & 1.22 & 0.064 \\
SS-SMT-048 & 1.22 & 1.22 & 0.048 \\
SS-SMT-400 & 1.22 & 1.22 & 0.4 \\
MS-RGH-064-AGE & 14.33 & 9.30 & 0.064 \\
\hline Note: 1. $\sigma_{\mathrm{n}}^{\prime}=200 \mathrm{kPa}$; 2 The numbers, $-048,-064,-400$ indicate the \\
applied shearing rates in mm/minute.
\end{tabular}

\subsection{Ring shear tests}

The ring shear apparatus described by [20] and shown in Fig. 2 was used to investigate the large-strain interface shearing behaviour of chalk. The samples were placed, consolidated and tested to match the conditions applying to driven offshore piles.

As recommended by [16]. An initial fast shearing stage was imposed, to mimic pile installation, followed by slow shearing to a displacement of $50 \mathrm{~mm}$ over 2 days. As summarised in Table 2, thirteen experiments were carried out at normal effective stress levels of 100$400 \mathrm{kPa}$, using MS and SS interfaces with $\mathrm{R}_{\mathrm{a}}$ values which ranged from 1- 15.1 $\mu \mathrm{m}$ (SMT, STD \& RGH).

One of the ring shear tests on a MS interface was held under constant normal effective stress (of 200kPa) post-consolidation for 25 days, prior to shearing. Vertical displacements of the specimens under short- and long-term consolidation (creep) were monitored continually. 
Table 2 Bishop ring shear interface testing programme

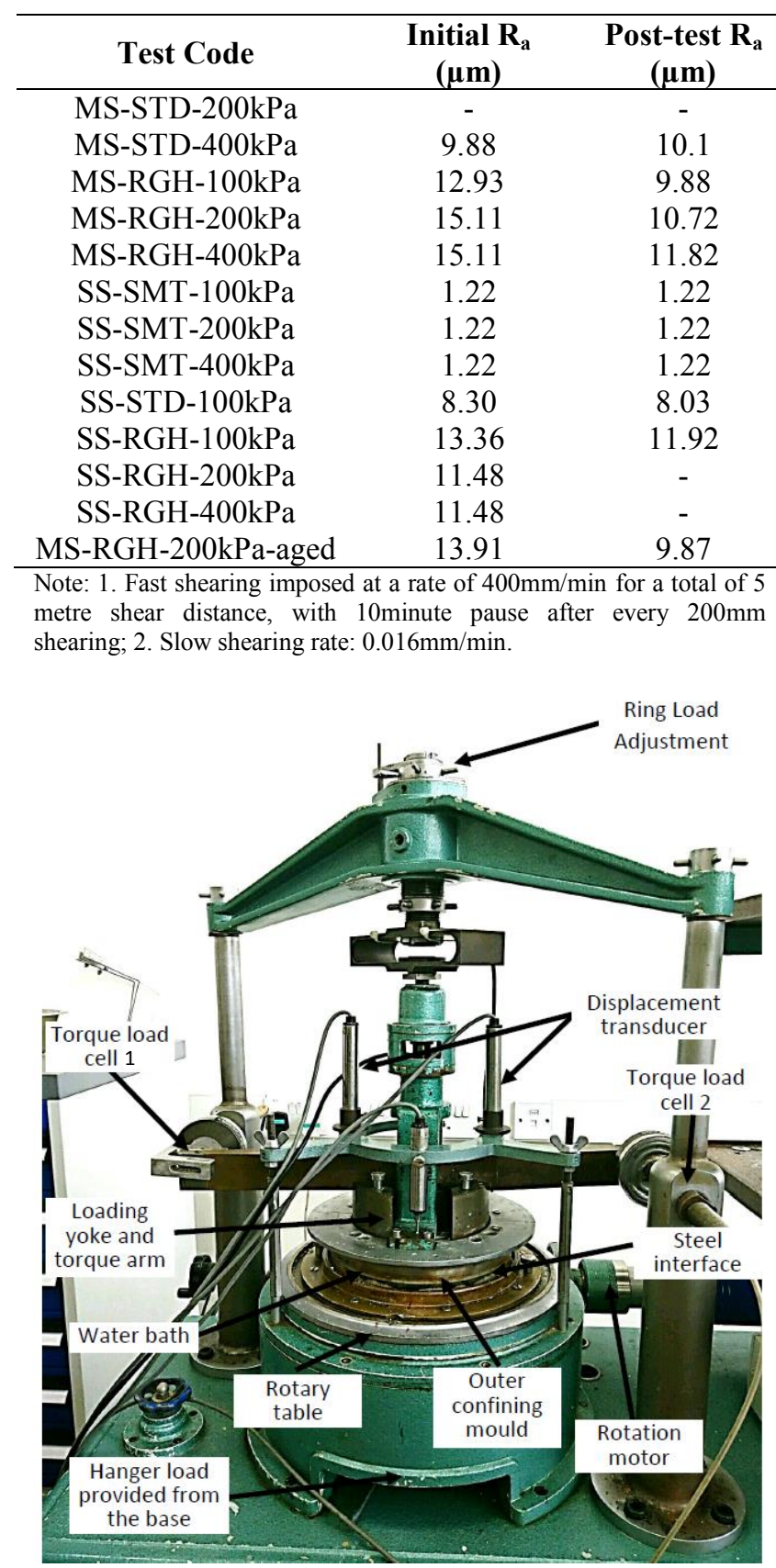

Fig. 2 Bishop Ring Shear apparatus at Imperial College

\section{RESULTS}

\subsection{Direct shear tests}

The ranges of residual $\left(\delta_{\mathrm{r}}^{\prime}\right)$ angles obtained from the direct shear tests are summarised in Table 3. No distinct peaks were observed and for the "young" (unaged) specimens $\delta_{\mathrm{r}}^{\prime}$ ranged from 27 to $32^{\circ}$ under $200 \mathrm{kPa}$ normal stress. The $\delta_{r}^{\prime}$ angles were insensitive to the interface steel type and roughnesses. Fig. 3 (a) plots the direct shear $\delta_{r}^{\prime}$ angles (at $10 \mathrm{~mm}$ displacement) normalised by remoulded chalk $\varphi^{\prime}$ (taken as $33^{\circ}$ ) against the relative roughness $R_{n}\left(=R_{a} / D_{50}\right)$. $[25,26]$ showed that failure tends to occur within in the sand mass once $R_{n}$ exceeds a critical roughness ratio $\mathrm{R}_{\text {crit }}(\approx 0.1)$. The peak stress ratio becomes independent of the interface roughness at higher $R_{n}$ values. Taking $D_{50}$ as of 3 to $6 \mu \mathrm{m}$ for the chalk indicates that $R_{n}$ values of 0.9 to 4.8 applied in the unaged MS tests and 0.2 to 4.3 for the SS tests, ratios that all exceeded $\mathrm{R}_{\text {crit }}$. The $\delta_{\mathrm{r}}^{\prime} / \varphi^{\prime}$ ratios observed experimentally all exceeded 0.8 , but fell below unity. However, failure appeared to develop primarily within the chalk mass, rather than by sliding at the interface. The MS interface test that was aged under constant normal effective stress for 38 days, showed a significant increase in $\delta_{r}^{\prime}$ of approximately $5.3^{\circ}$ compared to the unaged test conducted under the same conditions.

Table 3 Interface friction angle obtained in direct shear tests

\begin{tabular}{cc}
\hline Test Code & Friction angle $\boldsymbol{\delta}^{\prime}{ }_{\mathbf{r}}$ \\
\hline SS-SMT-400 & $27.3^{\circ}$ \\
SS-SMT-048 & $27.7^{\circ}$ \\
SS-SMT-064 & $27.8^{\circ}$ \\
SS-RGH-064 & $31.3^{\circ}$ \\
MS-SMT-064 & $27.5^{\circ}$ \\
MS-RGH-064 & $31.9^{\circ}$ \\
MS-RGH-064-aged & $37.2^{\circ}$ \\
\hline
\end{tabular}

\subsection{Ring shear tests}

The twelve ring shear tests performed on "young" chalk samples showed $\delta_{\text {peak }}^{\prime}$ and $\delta_{r}^{\prime}$ values that varied modestly with both $\mathrm{R}_{\mathrm{a}}$ and normal stress level, giving $\delta_{\text {peak }}^{\prime}=33^{\circ}$ $\pm 2^{\circ}$ and $\delta_{r}^{\prime}=32^{\circ} \pm 2^{\circ}$ after $40 \mathrm{~mm}$ of shear displacement (see Table 4). The ring shear angles were significantly higher than those seen in direct shear tests under the same conditions, reflecting the potential impact of the fast shearing and particle crushing developed during the tests' pre-conditioning stages as well as the larger displacements achieved in the ring-shear apparatus.

Table 4 Interface friction angle obtained in ring shear tests at various displacement level

\begin{tabular}{ccc}
\hline Test Code & \multicolumn{2}{c}{$\begin{array}{c}\text { Chalk-steel interface } \\
\text { friction angle, } \boldsymbol{\delta}^{\prime}\end{array}$} \\
& $\boldsymbol{\delta}_{\text {'peak }}^{\prime}$ & $\boldsymbol{\delta}^{\prime}{ }^{{ }^{\prime}}$ \\
\hline MS-STD-200kPa & $33.4^{\circ}$ & $32.8^{\circ}$ \\
MS-STD-400kPa & $35.8^{\circ}$ & $33.8^{\circ}$ \\
MS-RGH-100kPa & $31.5^{\circ}$ & $31.8^{\circ}$ \\
MS-RGH-200kPa & $33.2^{\circ}$ & $31.6^{\circ}$ \\
MS-RGH-400kPa & $35.6^{\circ}$ & $35.0^{\circ}$ \\
SS-SMT-100kPa & $29.8^{\circ}$ & $26.2^{\circ}$ \\
SS-SMT-200kPa & $30.5^{\circ}$ & $30.5^{\circ}$ \\
SS-SMT-400kPa & $31.5^{\circ}$ & $31.5^{\circ}$ \\
SS-STD-100kPa & $31.0^{\circ}$ & $29.7^{\circ}$ \\
SS-RGH-100kPa & $31.4^{\circ}$ & $30.2^{\circ}$ \\
SS-RGH-200kPa & $33.8^{\circ}$ & $32.2^{\circ}$ \\
SS-RGH-400kPa & $35.5^{\circ}$ & $33.9^{\circ}$ \\
MS-RGH-200kPa-aged & $36.0^{\circ}$ & $34.5^{\circ}$
\end{tabular}

Note: 1. Residual friction angle $\delta_{r}^{\prime}$ taken at a shearing displacement of $40 \mathrm{~mm} ; 2$. Friction angle at other displacement levels can be referred to [24]. 
Granular particles in contact with pile shafts must dilate away from the interface to permit sliding to occur. Fig. 3 (b) plots the maximum observed dilation $\Delta \mathrm{r}$ versus $\mathrm{R}_{\mathrm{n}}$ for the ring shear tests. Tests employing MS interfaces showed that $\Delta \mathrm{r}$ ranged from 14 to $24 \mu \mathrm{m}$, equivalent to 0.9 to 1.9 times $\mathrm{R}_{\mathrm{a}}$. The SS interface tests indicated $\Delta \mathrm{r}$ of 6 to $25.5 \mu \mathrm{m}$, equivalent to between 0.4 and 2.2 times $R_{a}$. No tendency was observed for $\Delta r$ to increase with $R_{n}$. Finding similar values of $\Delta r$ at all roughnesses is consistent with shearing occurring within the chalk mass, where dilation is largely independent of the interface properties. However, the laboratory 'dilative' movements exceed those inferred from field measurements with instrumented piles; see [2].

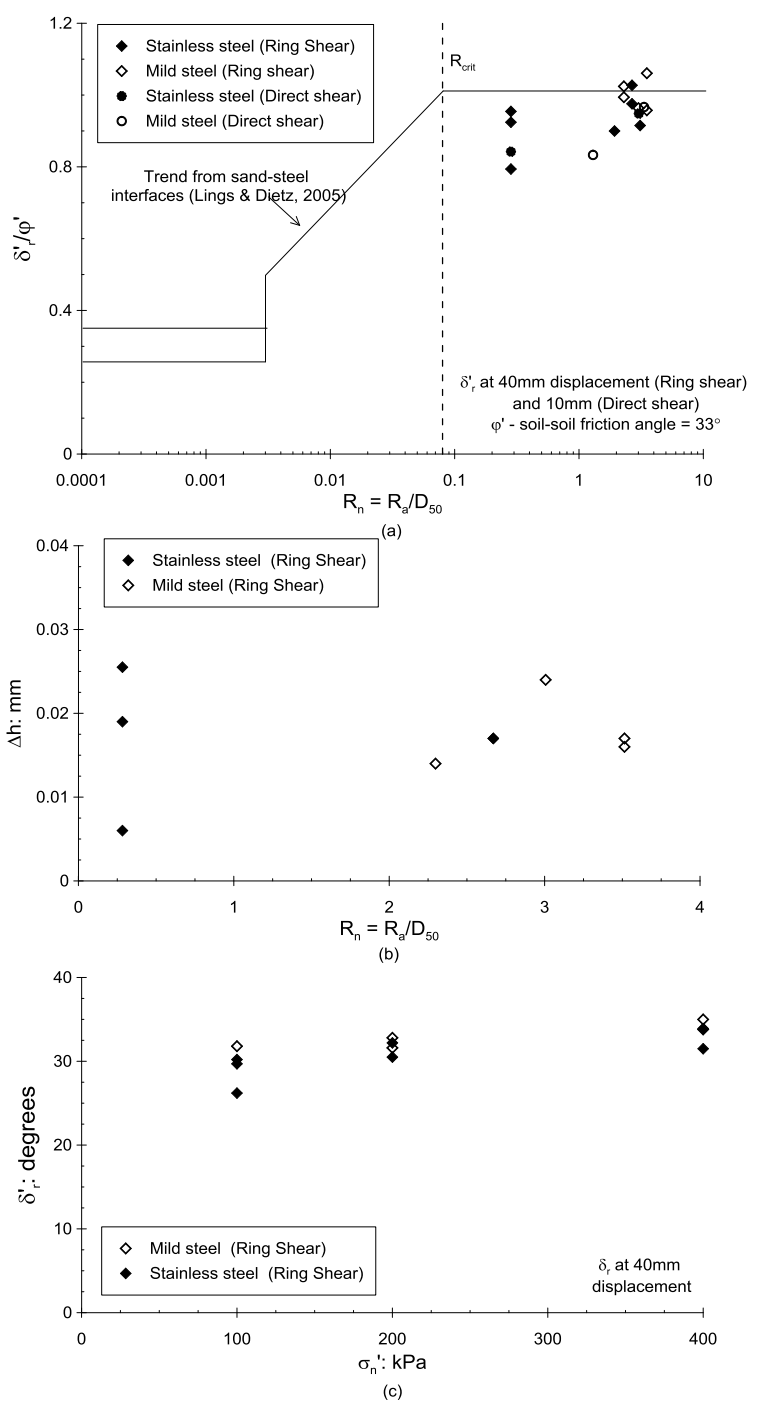

Fig. 3 (a) Effect of relative roughness on $\delta^{\prime}$ in ring shear and direct shear tests normalised by the chalk-chalk friction angle (b) change in sample height versus relative roughness in ring shear tests and (c) ultimate interface angle in ring shear tests versus stress level (Figure from [27])

Both $\delta_{\text {peak }}^{\prime}$ and $\delta_{r}^{\prime}$ appeared to increase with stress level, as shown for example by the 100 and $400 \mathrm{kPa}$ normal stress MS-STD and MS-RGH tests. As shown in Fig. 3 (c), the magnitude of increase in $\delta^{\prime}$ was highest between 100 and $200 \mathrm{kPa}$ and appeared to level off between 200 and $400 \mathrm{kPa}$, although [19] suggest that more significant reductions may apply under much higher normal stress levels.

Fig. 4 (a) illustrates the impact of ageing on interface friction angle by plotting the shearing resistance trends from a "young" specimen tested under $200 \mathrm{kPa}$, alongside a matching "aged" test, which mobilised $\delta_{\text {peak }}^{\prime}$ and $\delta^{\prime}$ r angles $\left(36\right.$ and $\left.34.5^{\circ}\right) 2$ to 3 degrees higher than the "young" test. Fig. 4 (b) shows the corresponding changes in sample height, $\Delta \mathrm{h}$. While both tests showed dilation before contracting to ultimate conditions, the aged interface manifested far less contraction under large displacement shearing.
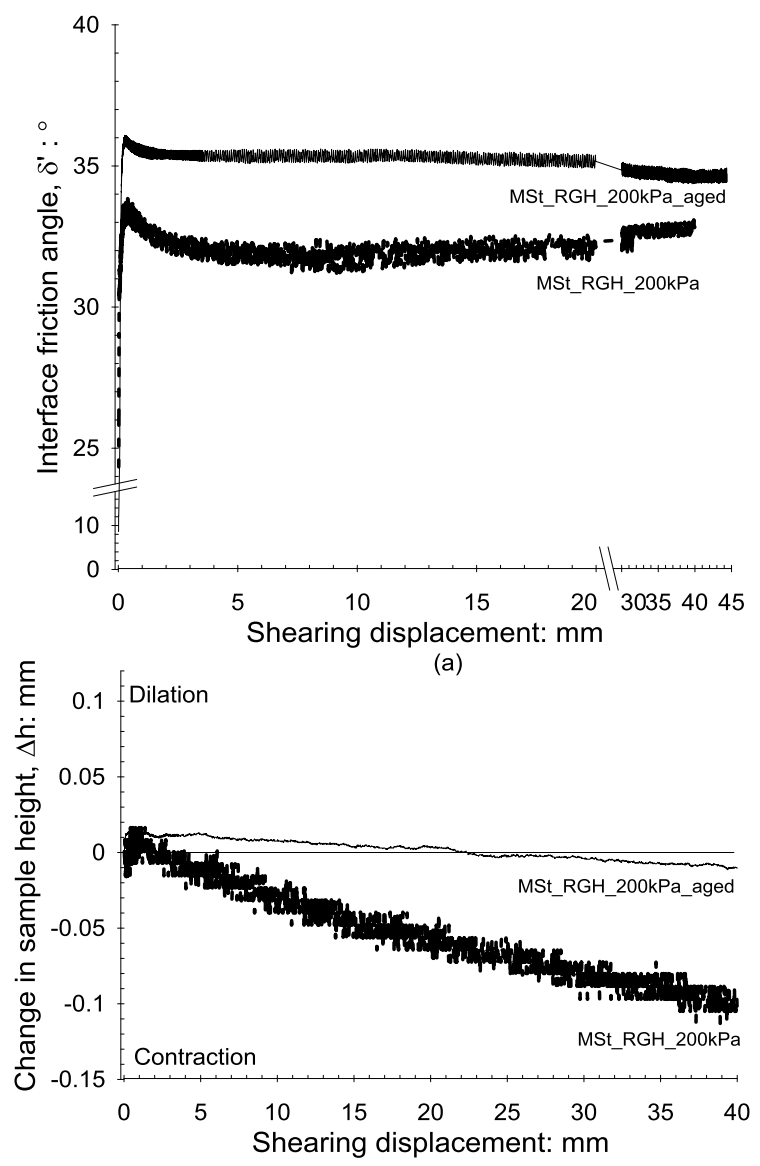

(b)

Fig. 4 Comparison between aged and unaged interface ring shear tests (a) interface friction angle versus displacement (b) change in sample height (Figure from [27])

On dismantling the aged test, green, turning to ochre coloured rust was observed on the interface, which had also diffused into the sample (Fig. 5) possibly disrupting the pre-formed shear mechanism and forcing a new mechanism to develop in the chalk under a modified set of chemical conditions. Visual observation and sample handling confirmed local changes in properties and a significant increase in strength. It was no longer possible to remould either the direct shear or ring shear chalk specimens by thumb pressure after the end of testing. 


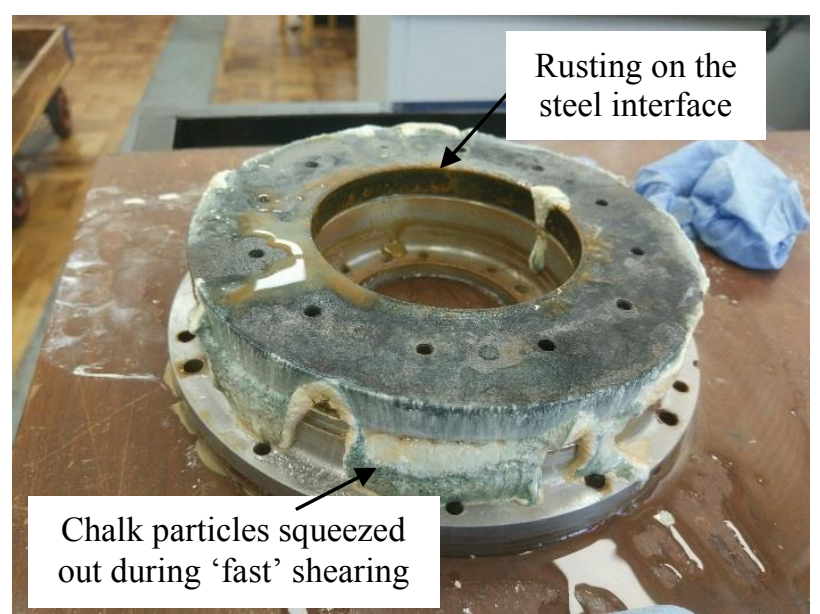

Fig. 5 Confining ring, chalk sample and interface at the end of the ring shear ageing test

\section{CONCLUSIONS}

This paper has presented the results of an investigation into the interface shearing behaviour of remoulded puttified chalk. Samples of low-to-medium density grade B2/B3 chalk taken from a test site in Kent, UK were tested in direct shear and ring shear apparatus, considering a range of interface materials and interface roughnesses. Ageing tests were also performed in both apparatus in which specimens were allowed to age under constant normal effective stress for between 25 and 38 days prior to shearing.

The experiments performed lead to the following primary conclusions:

(1) Consolidation occurs almost instantaneously in the chalk specimens, reflecting the high permeability of the predominantly silt-sized material;

(2) The interface shear angles $\delta^{\prime}$ obtained fell between $26^{\circ}$ and $37^{\circ}$, with most exceeding $30^{\circ}$; the ring shear tests led to higher angles than the direct shear experiments;

(3) The relative roughness ratios applying to the chalk and interfaces all exceed the critical $\mathrm{R}_{\text {crit }}=0.1$ limit defined previously for sands, above which shearing tends to occur within the soil mass;

(4) The values of $\delta_{r}^{\prime} / \varphi^{\prime}$ generally fell between 0.8 and 1.05 , with higher ratios emerging from the ringshear tests and indicating failure occurring within the chalk mass rather than at the interface;

(5) Tests on young specimens led to similar $\delta_{r}^{\prime}$ values from MS and SS interfaces at the same stress levels and roughness grades;

(6) Both $\delta_{\text {peak }}^{\prime}$ and $\delta_{r}^{\prime}$ also appeared to increase with normal effective stress level up to $400 \mathrm{kPa}$, with the greatest rates of change applying between 100 and $200 \mathrm{kPa}$;

(7) The interface shear strength of chalk tends to increase with time when MS interfaces are employed. Samples aged under constant normal effective stress and at constant water content developed increases in $\delta_{\mathrm{r}}{ }^{\prime}$ of 3 and $5^{\circ}$ over ageing periods of 25 and 38 days under direct shear and ring-shear test conditions. These changes appear to be related to chemical reactions at the interface that may not be expected in tests involving stainlesssteel (SS)interfaces.

It is important to note that intact chalk is a sensitive and variable geomaterial that can manifest significantly different stress- and displacement-dependent interface shearing characteristics when sheared from its intact 'very soft rock' state (as investigated by for example [19]) and when sheared after consolidation and/or extensive pre-shearing after previous de-structuration to a remoulded or 'putty' state. Rational assessment of any "conditioning" processes (such as pile driving, dynamic percussion, pre-shearing and ageing) that may occur is critical when designing specific laboratory testing programmes to derive representative interface shearing parameters for use in the design of driven or bored piles, or indeed gravity base foundations.

The chalk samples were kindly provided by Dr. Andrea Diambra. The Authors are also indebted to Mr. Steven Ackerley and Mr. Graham Keefe for their technical advice and assistance. Mr. Haoruo Chen is also acknowledged for his support of the laboratory testing.

\section{References}

1 R. M. Buckley, R. J. Jardine, S. Kontoe, D. Parker \& F. C. Schroeder. Ageing and cyclic behaviour of axially loaded piles driven in chalk. Géotechnique, 68, No. 2, https://doi.org/10.1680/jgeot.17.P.012: 146-161 (2018)

2 R. M. Buckley, R. J. Jardine, S. Kontoe \& B. M. Lehane (). Effective stress regime around a jacked steel pile during installation ageing and load testing in chalk. Can. Geotech. J. doi: 10.1139/cgj-20170145, doi: 10.1139/cgj-2017-0145 (2018)

3 A. J. Bowden, T. W. Spink \& R. N. Mortimore. The engineering description of chalk: its strength, hardness and density. Q. J. Eng. Geol. Hydrogeol., 35, No. 4: 355-361 (2002)

4 P. Carotenuto, V. Meyer, P. J. Strøm, Z. Cabarkapa, H. St. John, \& R. J. Jardine. Installation and axial capacity of the Sheringham Shoal offshore wind farm monopiles - a case history. Proc. BGA Conf. Engineering in chalk (under review) (2018)

5 F. Ciavaglia, J. Carey \& A. Diambra. Time-dependent uplift capacity of driven piles in low to medium density chalk. Géotechnique Letters, 7, No. March: 1-7 (2017)

6 L. J. Doughty, R. M. Buckley \& R. J. Jardine. Investigating the effect of ageing on the behaviour of chalk putty. Engineering in Chalk, London, UK: 695-701 (2018)

7 A. Muir Wood, B. Mackenzie, D. Burbury, M. Rattley, C. R. I. Clayton, M. Mygind, K. Wessel Andersen, C. Le Blanc Thilsted \& M. Albjerg Liingaard. Design of large diameter monopiles in chalk at Westermost Rough offshore wind farm. Poc. 3rd Conf. Frontiers in Offshore Geotechnics, Oslo, Norway: 723-728 (2015) 
8 A. de Raguenel (). Stabilite des ramblais crayeux de grande hauteur. La craie: Bull. Liason Labo. P. de. Ch., No. Special V: 165-169 (1973)

9 L. Lake. Engineering Properties of Chalk with Special Reference to Foundation Design and Performance. PhD Thesis, University of Surrey, Surrey, UK (1975)

10 C. R. I. Clayton. Some properties of remoulded chalk. Proc. 9th Intl. Conf. Soil Mech. Found Eng., Tokyo, Japan: 65-68 (1977)

11 C. R. 1. Clayton. Chalk as Fill. PhD Thesis, University of Surrey, Surrey, UK (1978)

12 S. P. S. Bundy. Geotechnical properties of chalk putties. PhD Thesis, University of Portsmouth, Portsmouth, UK (2013)

13 G. Bialowas, A. Diambra, \& D. Nash. Small strain stiffness evolution of reconstituted medium density chalk. Proc. 1st IMEKO TC4 Intl. Workshop on Metrology for Geotechnics, Benevento, Italy: 162167 (2016)

14 J. G. Potyondy. Skin friction between various soils and construction materials. Géotechnique, 11, No. 4: 339-353 (1961)

15 A. Gaba, S. Hardy, L. Doughty, W. Powrie, \& D. Selemetas. Guidance on embedded retaining wall design, CIRIA (2017)

16 R. J. Jardine, F. C. Chow, R. Overy, \& J. R. Standing. ICP design methods for driven piles in sands and clays, London: Thomas Telford (2005)

17 R. J. Jardine, R. M. Buckley, S. Kontoe, P. Barbosa, \& F. C. Schroeder. Behaviour of piles driven in chalk. Engineering in Chalk. ICE Publishing: 3351, (2018)

18 T. M. H. Le, G. R. Eiksund \& P. J. Strøm. Characterisation of Residual Shear Strength at the Sheringham Shoal Offshore Wind Farm. Proc. 33rd Intl. Conf. Ocean, Offshore and Arctic Eng., San Francisco, California: 1-9 (2014)

19 A. Ziogos, M. Brown, A. Ivanovic, \& N. Morgan. Chalk-steel interface testing for marine energy foundations. Proc. of the ICE Geotech. Eng, 170, No. 3: 285-298 (2017)

20 A. W. Bishop, G. Green, V. K. Garga, A. Andresen, \& J. Brown. A new ring shear apparatus and its application to the measurement of residual strength. Géotechnique, 21, No. 4: 273-328 (1971)

21 R. J. Jardine, R. M. Buckley, B. Byrne, S. Kontoe, R. Macadam \& K. Vinck. The ALPACA research project to improve driven pile design in Chalk. Proc. 17th European Conference on Soil Mechanics and Geotechnical Engineering, in preparation, Reykjavik, Iceland (2019)

22 J. M. Hancock. The petrology of the Chalk. Proceedings of the Geologists' Association, 86, No. 4: 499-535 (1975)

23 C. R. I. Clayton. The mechanical properties of the Chalk. Proc. Intl. Chalk Symposium, Brighton, UK: 213-233 (1990)
24 D. L. H. Chan. Laboratory investigation of chalksteel interface shearing. MSc Thesis, Imperial College, London, UK (2017)

25 M. Uesugi and H. Kishida. Frictional resistance at yield between dry sand and mild steel. Soil and Foundations, 26, No. 4: 139-149 (1986)

26 R. J. Jardine, B. M. Lehane \& S. J. Everton. Friction coefficients for piles in sands and silts. In Offshore Site Investigation and Foundation Behaviour. (Ardus D. A., Clare D., Hill A., Hobbs R., Jardine R. J. and Squire J. M. (eds)) Society for Underwater Technology, Dordrecht, pp. 661-677 (1992)

27 R. M. Buckley. The axial behaviour of displacement piles in chalk. $\mathrm{PhD}$ Thesis, Imperial College London, London, UK (2018) 